\title{
International Representation in the Psychological Literature
}

\author{
Robert Bauserman \\ University of Michigan, Ann Arbor, USA
}

\begin{abstract}
The author searched PsycLit records to examine the representation of psychological research from outside the US and changes in international representation over time. American research dominates, but international representation has increased since 1975. Western Europe, Japan, Australia, and Israel in particular have become better represented. In contrast, developing nations have remained poorly represented for most of the time period examined. Relative national influence may accurately reflect the numbers of psychologists in general, and research psychologists in particular, in each nation. Psychologists in developing nations also focus on teaching, clinical, and social issues, and have few resources for research activities. International representation is likely to continue increasing.
\end{abstract}

Cette étude utilise la banque de données PsycLit pour analyser la représentation de la recherche en psychologie faite à l'extérieur des Etats-Unis et les changements dans la représentation internationale au fil du temps. La recherche américaine domine mais la représentation internationale a augmenté depuis 1975. L'Europe de l'Ouest, le Japon, l'Australie et Isräel en particulier sont mieux représentés qu'ils ne l'étaient dans le passé. Par contre, les nations en voie de développement sont demeurées peu représentées pour toute la période étudiée dans cet article. L'influence nationale relative pourrait refléter le nombre de psychologues, en général et le nombre de chercheurs en psychologie, en particulier. Les psychologues des nations en voie de développement se concentrent sur l'enseignement et les problèmes cliniques et sociaux et disposent de peu de ressources pour des activités de recherche. Il est probable que la représentation continue à s'accroître.

\section{INTRODUCTION}

Abstracting services, both print and electronic, are now a major research tool for psychologists and specialists in other disciplines. The availability of specialized computer databases has made literature searches for research on specific topics quick and efficient. An obvious limitation, however, is that the researcher will only be able to locate material from sources that the publishers of information databases have decided to use. Research published in journals not included in major abstracting and reference services will remain obscure and unnoticed by most investigators unless they have access to actual physical copies of the journal. For American psychologists, who make up approximately a half of all psychologists in the world (Rosenzweig, 1992), access to psy- chological research from other nations will depend both on publication of foreign research in American journals and on indexing of foreign psychology journals in database services.

Across most scientific disciplines, abstracting and indexing services clearly favour publications from the United States and other Western nations (Gibbs, 1995). Publishers of science and medical journals in developing nations encounter substantial difficulty in getting their journals included in the major general science index, the Science Citation Index (SCI). Gibbs found that less than $2 \%$ of the 3300 journals indexed in SCI were published in developing nations. Furthermore, participation in the international scientific literature covered in SCI was minuscule for most developing nations. The United States alone accounted for $30.8 \%$ of the mainstream journal articles indexed in SCI in

Requests for reprints should be sent to Dr. Robert Bauserman, Department of Psychology, East Hall, University of Michigan, Ann Arbor, MI 48109, USA. 
1994, and the top 12 nations on the list accounted for $79.9 \%$ of the articles.

In the field of psychology, Psychological Abstracts serves as a primary research tool for those interested in exploring the psychological literature. Electronic versions of Psychological Abstracts include PsycLit (a CD-ROM version) and PsycInfo (an on-line version). The primary questions that motivated the current research were (1) to what extent is research from outside the United States represented in the main psychological abstracting service, and (2) to what extent does this representation fairly or proportionately reflect psychological research activity outside the United States.

The electronic versions of Psychological Abstracts were chosen because of their exclusive focus on the psychological literature. Numerous other electronic databases exist, including some which index psychology journals (e.g. Current Contents). However, because these other databases include journals from multiple fields of study, identifying and analyzing only the psychology journals presents difficulties in narrowing and focusing one's search. For example, Current Content's Social and Behavioural Sciences file lists titles in sociology, anthropology, and other areas. Furthermore, because of the exclusive focus on psychology, the list of psychology journals indexed on PsycLit/PsycInfo is more comprehensive than that of any other database. As of 1996, a total of 1330 psychology and psychology-related journals were indexed in PsycLit/PsycInfo (Gosling, 1996); this compares with a total of approximately 1500 journals in all the social and behavioural sciences indexed in Current Contents' Social and Behavioural Sciences file. The PsycLit CD-ROM version of Psychological Abstracts was chosen as the electronic database for this research for several reasons: (1) the ease of use and range of search options available, including institutional affiliation of authors and language of publication; (2) the ability to easily combine multiple searches, such as a particular year of publication and a particular nation of origin; (3) the overlap with PsycInfo, such that findings would be relevant to authors with access to only one of the two electronic databases; and (4) the status of Psychological Abstracts and its electronic versions as an official American Psychological Association publication, representing journals and research literature deemed sound enough for "official recognition."
Using the PsycLit database itself, only two previous articles were found that analyzed international literature in the PsycLit database (Brozek $\&$ Siegler, 1989, 1991). These researchers were motivated to investigate the availability of such literature by the decision of the American Psychological Association in 1987 to drop non-English publications from the text version of Psychological Abstracts, but to retain such literature in the electronic formats of PsycLit and PsycInfo. Examining the percentage of abstracted articles originally written in English and various nonEnglish languages and published in the years 1983-1986, 1987, and 1988, Brozek and Siegler (1989) found that for 1983-1986, 12.6\% of abstracts were of non-English language articles (primarily articles written in French, German, and Spanish). For articles published in 1987, however, only 1.4\% were non-English, and for 1988 only $1.6 \%$. Later follow-up (Brozek \& Siegler, 1991) revealed that this near-disappearance of abstracts of the non-English literature was a temporary condition. With a more recent PsycLit disk, the percentage of non-English literature in the abstracts was $13.6 \%$ for the $1983-1986$ period; $14.1 \%$ in $1987 ; 14.3 \%$ in 1988 ; and $6.2 \%$ in the incompletely indexed 1989 abstracts. The authors noted the lower $6.2 \%$ rate for the most recent year was probably the result of longer processing lags for non-English literature (a possible explanation for their earlier findings as well). Thus, representation of non-English literature in PsycLit remained at a relatively constant rate throughout the 1980 s.

A serious limitation of Brozek and Siegler's analyses is that the representation of international psychology in PsycLit may not be reflected accurately by the percentage of non-English literature abstracts. Psychologists in several countries where psychology has a strong presence (e.g. Great Britain) have English as their first language. Furthermore, English is recognized as a common scientific language, and many scientists in both the developed and developing nations use English as a second language. Thus, writing for publication in English-language journals is possible for many psychologists around the world. In addition, the languages appearing most commonly after English (Brozek \& Siegler, 1989, 1991) include Spanish and French, both of which are primary or official languages of numerous countries in the developing world, including Latin America and Africa. In short, publication outlets in either a first or second language are available to psychological 
researchers around the globe. An alternative way to analyze the international presence in PsycLit is through examination of countries listed in the IN, or institution field, of individual PsycLit records. For each abstract, this field specifies both the names of author's institutions and the countries in which they are located. For any individual country, it is possible to search for the occurrence of that specific country's name in the institution field. This approach was used in the current study.

\section{METHOD}

To measure representation of countries outside the US in the PsycLit abstracts, country-by-country searches of the IN (institution) field were conducted for each five-year period between 1975 and 1990 and also for 1994. The PsycLit disks covering the period up to June 1996 were used. 1994 was chosen as the most recent publication year for analysis because it was expected that many 1995 publications would not yet have been indexed (especially from non-English language periodicals, which were expected almost exclusively to represent institutions outside the US). In fact, only 27,017 articles published in 1995 were listed on the June 1996 disk, compared to 41,720 articles published in 1994 , indicating the time lag in processing publications into PsycLit. After locating all records containing 1994 in the publication year, searches were conducted for articles with specific country names in the IN field and the resulting $N$ s were recorded. A similar procedure was followed for abstracts with the publication years 1990, 1985, 1980, and 1975 .

A total of 113 individual country names were used in searches. Countries not searched were primarily smaller nations, such as the European "micro-states" and small island nations of the Caribbean Sea and the Pacific and Indian Oceans. These countries were excluded because of their small size and limited number of post-secondary educational institutions. For Great Britain, searches were conducted separately for institutions in England, Scotland, and Wales, which are identified separately in the IN record fields. Searches for the US were conducted specifically for 1985, 1990, and 1994. Prior to these years, American institutions were identified by state abbreviations rather than by the term "US"; rather than search each 50 states individually, records unaccounted for by other nations were assumed to represent US institutions. This procedure could slightly inflate the US percentage of abstracts for the 1975 and 1980 target years, but not the accuracy of the percentage representation for other nations.

As a secondary approach, language of publication for each year selected was also analyzed. This was done to enable comparison with Brozek and Siegler's $(1989,1991)$ results for the $1983-$ 1990 period. Finally, the journals indexed in PsycLit were tabulated from the listings provided in the print version of Psychological Abstracts.

\section{RESULTS}

Table 1 lists the results of the country-by-country search for the 5-year periods 1975 to 1990 and for 1994. All countries appearing in the institution field for more than $1 \%$ of articles for any year searched are listed separately. Remaining countries are grouped by region.

Although no statistical tests of trends were conducted, some changes are apparent. First, the United States share of indexed abstracts declined steadily from almost $70 \%$ in 1975 to $53.9 \%$ in 1994. Representation of several other areas has increased steadily, including Western Europe in general, Australia and New Zealand, Japan and East Asia, and Israel. Canadian representation fluctuated, but the overall 1975-1994 increase was small. Overall representation remained very low from 1975 to 1994 for Southeast Asia, Latin America, and sub-Saharan Africa, all regions composed primarily of developing nations. Finally, Eastern European representation was steady from 1975 to 1990 but dropped by nearly $60 \%$ between 1990 and 1994, perhaps due to political instability and change in that region.

In addition to the United States, only 14 other nations accounted for more than $1 \%$ of indexed abstracts in any selected year. Half of these were in Western Europe. It seems that American researchers have access via PsycLit and PsycInfo to growing numbers of research articles from outside the US, but the primary contributors are still the industrialized nations such as Western Europe, Canada, and Japan. The top 12 nations (including the US) accounted for $89.5 \%$ of indexed abstracts in 1994 .

Although the country-by-country searches provide the most detailed information on international representation in psychology, the two other methods used give some additional insight. Table 2 lists original language of publication for abstracted articles. English-language articles were consistently $86 \%$ to $88 \%$ of the total for each 
TABLE 1

Percent of Articles in PsycLit Abstracts Originating from Each Nation or Region

\begin{tabular}{|c|c|c|c|c|c|}
\hline \multirow[b]{2}{*}{ Nation/Region } & \multicolumn{5}{|c|}{ Year } \\
\hline & $\begin{array}{c}1975 \\
N=21,794\end{array}$ & $\begin{array}{c}1980 \\
N=19,099\end{array}$ & $\begin{array}{c}1985 \\
N=37,838\end{array}$ & $\begin{array}{c}1990 \\
N=38,467\end{array}$ & $\begin{array}{c}1994 \\
N=41,720\end{array}$ \\
\hline United States & 69.5 & 65.8 & 64.1 & 54.7 & 53.9 \\
\hline Canada & 5.5 & 6.2 & 5.6 & 6.6 & 6.3 \\
\hline \multicolumn{6}{|l|}{ Western Europe } \\
\hline Great Britain & 5.6 & 6.0 & 6.4 & 6.9 & 8.7 \\
\hline Germany & 2.6 & 2.9 & 2.9 & 3.2 & 3.2 \\
\hline France & 1.6 & 1.9 & 1.9 & 2.2 & 1.8 \\
\hline Netherlands & 0.9 & 0.8 & 1.5 & 1.9 & 2.3 \\
\hline Italy & 0.9 & 1.2 & 1.6 & 1.7 & 1.9 \\
\hline Sweden & 1.0 & 0.9 & 0.9 & 1.1 & 1.2 \\
\hline Spain & 0.2 & 0.4 & 1.0 & 1.2 & 1.2 \\
\hline Others $^{a}$ & 2.6 & 2.4 & 2.7 & 3.2 & 3.7 \\
\hline \multicolumn{6}{|l|}{ Eastern Europe } \\
\hline USSR/CIS & 0.8 & 0.8 & 1.3 & 2.0 & 0.5 \\
\hline Czechoslovakia & 1.1 & 0.8 & 0.5 & 0.4 & 0.2 \\
\hline Others $^{b}$ & 1.4 & 1.4 & 1.1 & 0.9 & 0.6 \\
\hline \multicolumn{6}{|l|}{ East Asia } \\
\hline Japan & 1.2 & 1.4 & 1.5 & 1.9 & 2.2 \\
\hline Others ${ }^{c}$ & 0.0 & 0.1 & 0.2 & 0.3 & 0.5 \\
\hline \multicolumn{6}{|l|}{ Southeast Asia } \\
\hline India & 0.9 & 1.1 & 1.1 & 0.8 & 0.5 \\
\hline Others $^{d}$ & 0.3 & 0.3 & 0.3 & 0.4 & 0.6 \\
\hline Australia/New Zealand & 1.9 & 2.5 & 2.4 & 2.7 & 3.4 \\
\hline \multicolumn{6}{|l|}{ Middle East/North Africa } \\
\hline Israel & 0.8 & 1.0 & 1.2 & 1.3 & 1.4 \\
\hline Others $^{e}$ & 0.0 & 0.1 & 0.1 & 0.2 & 0.2 \\
\hline Sub-Saharan Africa ${ }^{f}$ & 0.2 & 0.7 & 0.5 & 0.4 & 0.5 \\
\hline Latin America ${ }^{g}$ & 1.0 & 1.0 & 1.5 & 1.5 & 1.2 \\
\hline
\end{tabular}

\footnotetext{
${ }^{a}$ Includes Austria, Belgium, Denmark, Finland, Greece, Iceland, Ireland, Norway, Portugal, Switzerland.

${ }^{b}$ Includes Bulgaria, Hungary, Poland, Romania, and Yugoslavia. The 1994 total for the Commonwealth of Independent States (CIS) includes Russia and all former Soviet republics.

${ }^{c}$ Includes China and Korea.

${ }^{d}$ Includes Bangladesh, Hong Kong, Indonesia, Malaysia, Pakistan, Philippines, Singapore, Taiwan, Thailand.

${ }^{e}$ Includes Iran, Iraq, Kuwait, Lebanon, Syria, Turkey, and all Arab nations on the Arabian peninsula and in North Africa.

${ }_{f}^{f}$ Includes all African nations except those in North Africa.

${ }^{g}$ Includes Mexico and all Central and South American countries.
}

5-year period from 1975 to 1990 , with only 1994 including a larger percentage of English articles. These results are nearly identical to the 1980s data reported by Brozek and Siegler (1989, 1991). The lower percentage of non-English articles for 1994 may reflect a lag in processing of foreign-language publications. However, a check of other years of publication in the 1990 s revealed that $89.9 \%$ of articles from 1991 were in English, as were $91.2 \%$ of articles for 1992 and $92.2 \%$ of articles for 1993. Articles published in German and French, the most common languages after English, also steadily declined as a percent of total articles indexed from 1975 to 1994 . Contin- ued examination of this apparent trend is necessary to determine if the dominance of English as a language of publication is increasing. Although English is clearly the dominant language, substantial numbers of articles originally in German, French, and Spanish are also abstracted.

The PsycInfo office of the American Psychological Association headquarters in Washington provided information on the journals currently indexed in PsycLit/PsycInfo (Gosling, 1996). As of 1996, a total of 1330 journals were being indexed. The journals covered were published in a total of 47 different countries, including some from every continent; 767 , or $57.7 \%$, were 
TABLE 2

Percent of PsycLit Articles in English and Other Languages $^{\mathrm{a}}$

Year

\begin{tabular}{lrrrrr} 
Language & 1975 & 1980 & 1985 & 1990 & 1994 \\
\hline English & 87.4 & 87.2 & 86.0 & 88.1 & 92.8 \\
German & 3.3 & 2.9 & 2.3 & 2.3 & 1.6 \\
French & 3.1 & 2.8 & 2.7 & 2.6 & 1.3 \\
Spanish & 1.2 & 1.1 & 2.1 & 1.5 & 1.0 \\
Others $^{b}$ & 5.1 & 6.0 & 6.9 & 5.5 & 3.3 \\
\hline
\end{tabular}

${ }^{a}$ Totals may not be precisely $100.0 \%$ because of rounding.

${ }^{b}$ Italian, Japanese, Chinese, Dutch, and Russian were the most common languages in the "Others" category for 1994.

published in the US. Another 400, or $30.1 \%$, were from Western European countries, including 167 from Great Britain. Canada, Australia, and New Zealand, all primarily English-speaking countries, contributed 51 more $(3.9 \%)$. Only $8.3 \%$ were published in the remainder of the world. The region with the least representation was Africa, with only six journals from the entire continent (all from South Africa, Nigeria, or Egypt) indexed in PsycLit. The PsycInfo office reported that these numbers have remained steady over the past several years, with a total of 1327 journals indexed in both 1995 and 1994. Thus, the coverage of nonUS journals is probably nearly identical for the 1994 publications analyzed in this report.

\section{DISCUSSION}

The first research question was to what extent psychological research from outside the US is represented in the PsycLit abstracting service, a major reference tool of American researchers. Clearly, American researchers and journals dominate PsycLit to a greater extent than even the US and Western dominance documented in the SCI. Approximately 54\% of indexed articles in PsycLit currently originate from US institutions, compared to $30.8 \%$ for the SCI (Gibbs, 1995), and almost $58 \%$ of indexed journals are published in the US. Nevertheless, international research does have substantial representation. Nearly half the articles indexed originate from institutions outside the US. PsycLit also provides access to abstracts of literally thousands of articles each year that are originally published in languages other than English, especially French, Spanish, and German. In addition, hundreds of non-US psychology and psychology-related journals are indexed. Most importantly, overall international representation has steadily increased over the past 20 years, as the proportion of articles originating from US institutions declined from a high of nearly $70 \%$.

The more difficult question to answer is the issue of whether or not foreign research is fairly or proportionately represented in PsycLit. The answer here seems to be a qualified yes. Although American institutions currently account for $54 \%$ of all indexed PsycLit abstracts, this representation is not very disproportionate compared to the world distribution of psychologists in general and research psychologists in particular. Approximately 250,000 out of 500,000 total psychologists in the world are located in the US (Rosenzweig, 1992), and among those psychologists primarily engaged in research, an estimated 35,000 out of a world total of 72,000 are based in the US. The international distribution of published articles may therefore fairly reflect the actual distribution of international research activity in psychology, because approximately one-half of the world's research psychologists are located in the US.

Another way of answering the question of fairness is examining whether or not nations with the most psychological resources are appropriately represented in PsycLit. In a rough calculation of the population density of psychologists in 42 nations around the world, Sexton and Hogan (1992) divided membership in psychological organizations by national populations. The United States ranked seventh on the list. Seven of the top ten nations were in Western Europe, including the Netherlands and Germany, both well-represented in Table 1. Israel ranked third on the list, and also appears well-represented in Table 1, especially considering its small population. Thus, the nations and regions that contribute most heavily to the research literature are primarily those with the greatest density of psychologists.

Not surprisingly, nations poorly represented in PsycLit include mainly those in Latin America, the Middle East and South Asia, and Africa. This lack of representation seems likely to be a consequence of the underdeveloped state of psychology in general in many of these nations. The bottom five nations on Sexton and Hogan's (1992) ranking of density of psychologists were all Asian or African countries. Under-representation of developing nations in Latin America, Asia, and Africa may also reflect the possibility that 
research activities are not a high priority for the few psychologists located in developing nations. For example, reviews of the state of psychology in such nations as Zimbabwe (Jordan, 1992), Pakistan (Ansari, 1992), and Uruguay (Giuria, 1992) emphasize a focus on teaching, clinical work, and social issues, and a lack of funding and resources for research activities.

Although American psychology, and psychologists, may rightly be criticized for frequently overlooking or disregarding contributions from other countries (e.g. Sexton \& Hogan, 1992), PsycLit provides access to a fair representation of research from throughout the world. As conditions improve and psychological science develops in such under-represented areas as Southeast Asia or Africa, the research contribution of these areas is likely to increase as well. There is a trend toward increasing numbers of psychologists outside the US (Rosenzweig, 1992; Sexton \& Hogan, 1992), and Sexton and Hogan (1992) predict continued rapid growth around the world and increased communication between American psychologists and the rest of the world psychology. Thus, American psychologists seem likely to experience increasing influence from the efforts of their colleagues around the world, and international representation in PsycLit will continue to rise, as it has done since the 1970 s.

Manuscript first received May 1996 Revised manuscript accepted October 1996

\section{REFERENCES}

Ansari, Z.A. (1992). Pakistan. In V.S. Sexton \& J.P. Hogan, International psychology: Views from around the world (pp. 324-330). Lincoln, NE: University of Nebraska Press.

Brozek, J., \& Siegler, S.L. (1989). History of international psychology in the unmaking: Abstracting nonEnglish periodical literature in the USA. Perceptual and Motor Skills, 68, 1205-1206.

Brozek, J., \& Siegler, S.L. (1991). History of international psychology revisited: Abstracting nonEnglish periodical literature in the USA. Perceptual and Motor Skills, 72, 1064-1066.

Gibbs, W.W. (1995). Lost science in the Third World. Scientific American, 273(2), 92-99.

Giuria, J.L. (1992). Uruguay. In V.S. Sexton \& J.P. Hogan, International psychology: Views from around the world (pp. 438-445). Lincoln, NE: University of Nebraska Press.

Gosling, G. (1996). Personal communication from American Psychological Association PsycInfo office, September 26.

Jordan, J. (1992). Zimbabwe. In V.S. Sexton \& J.P. Hogan, International psychology: Views from around the world (pp. 462-466). Lincoln, NE: University of Nebraska Press.

Rosenzweig, M.R. (1992). Psychological science around the world. American Psychologist, 47, $718-722$.

Sexton, V.S., \& Hogan, J.P. (1992). International psychology: Views from around the world. Lincoln, NE: University of Nebraska Press. 